\title{
Simplification: The Sims and Utopianism
}

\author{
Ann McGuire
}

$\mathrm{W}$ hile the emergent forms of visual digital media - spectacle cinema, computer animation, music video, arcade and computer games - are not solely the province of youth, young people are arguably those in the culture most involved with them. Indeed, it has been suggested that these new, electronically mediated spaces are the 'natural environment' of youth (Green and Bigum 1993, p.127). In such a cultural context, the role of these media in the production and negotiation of subjectivities requires the kind of theoretical analysis that has developed in relation to print fiction read by the young, and recent work has emerged that advocates comparative analysis of computer games and literary narrative (Zancanella 2000). Such comparisons must be tempered, however, by careful attention to the specific modality of gaming, a modality that has significant implications for the way the game positions the player as subject. For example, while simulation games, in which players construct interactive narratives in a model of the contemporary social environment, are in many ways structurally analogous to speculative fictions, the game mode must be taken into account in any analysis of the ways in which the player is positioned by them.

The Sims, currently the best selling computer game of all time, is a simulation in which players interact with a screen world, building and decorating houses, and striving to direct and control animated 3D figures as they find or lose employment, enter or leave relationships, and ultimately 'succeed' or 'fail' in life. While the digital technology which produces the cinematically realistic screen interface is historically unprecedented, the experience of playing The Sims has elements in common with that of reading narrative fiction, in that the game positions the player to identify with characters acting out scenarios of work and play in recognisable spatio-temporal settings. More specifically, the game's positioning of the player is arguably analogous to the reader-positioning effected by the speculative genre of utopian narrative fiction. The word 'utopia' punningly combines the Greek words 'eu'(good), 'ou'(no) and 'topia' (place) to signify 'the good place that is no place', so that utopian texts configure spatial and social arrangements which, by improving on those of the author's own context, position the reader to think critically about the inadequacies of that context for its subjects. The Sims, too, offers the experience of exploring spatial and social arrangements that seem to improve on the contemporary context, and thus the game potentially constitutes a site for active speculation about the ways in which the contemporary social environment positions its subjects. Ultimately, though, the nature of the gaming activity works to limit the opportunities for critical comparison. This paper explores the implications of the medium of the computer game in relation to the potentially utopian narrative project of The Sims, and analyses the cultural effects of the game's positioning of the player as similar to those of the 'degenerate utopianism'(Marin 1990, p.239) of postmodern spatial experiences such as Disneyland.

Theorisation of the nature and function of computer games is still an emerging disciplinary field. Some of its key figures argue that the specific modality of this new media form renders it so different in kind from more traditional media forms such as print narrative and cinema that the academic study of games requires an entirely new disciplinary project, variously described as 'game studies' or 'ludology'. Espen Aarseth, for example, has coined the term 'ergodic' to articulate the textual specificity of the computer game, deriving the word from the Greek words 'ergon' and 'hodos', meaning 'work' and 'path' (Aarseth 1997, p.1). He defines games as ergodic because the novelty of cybernetic systems is that they are information feedback loops capable of generating different semiotic sequences, so that:

the experienced sequence of signs does not emerge in a fixed, predetermined order decided by the instigator of the work, but is instead one actualization of many possible routes within what we may call the event space of semiological possibility.

(Aarseth 1997, p.33)

Thus 'the ergodic work is individualised or quasiindividualised on the audience level' (p.31). Aarseth therefore argues against what he describes as a kind of colonising of game studies by literary or cultural theory. As the discipline of game studies develops, however, persuasive arguments are emerging to suggest that theoretical perspectives derived from cultural and literary studies may be helpful, even necessary, complements to game studies. Christopher Douglas, for example, argues that 
it is possible to read computer games as modally specific in their ergodic structure, while also drawing on reading practices from literary and cultural studies, on the grounds that 'literary studies' experience with reading designed worlds might help us to understand how digital games situate their operators' (Douglas 2002, p.5).

Even though the work of theoretical boundary setting is still in progress, the powerful effects of the gaming experience on the construction of personal and cultural identity in contemporary youth culture means that the task of reading and analysing computer games needs to be undertaken. A form of theoretical bricolage seems defensible in such a conjuncture. For example, Aarseth's argument that the ergodic text is individualised on the audience level is clearly relevant to a simulation game such as The Sims that offers players opportunities to create families and make lives for them, and then press a 'Quit' icon and play the game again with new families and new lives. But computer games do not offer infinitely open-ended semiotic structures. Rules of gameplay, such as the model of the social that informs the programming of The Sims, set the parameters of players' experience of the game, and those rules are themselves constructed in relation to specific social and historical contexts. Lev Manovich, like Aarseth, argues that the generation of multiple semiotic sequences is a defining characteristic of a computer game, so that its 'branching interactive program' allows the player to forge unique trajectories (Manovich 2001, p.128). However, Manovich sees broader cultural implications in the ergodic nature of the game, in that it naturalises a logic of selection well suited to the construction of identities in post-industrial societies. Thus, while games are ergodic in their structural possibilities, their ergodic nature means that, like literary texts, they are also culturally constructed semiotic systems that control the play of meaning and position their players in ways related to their broader cultural context. In both instances, text and reader, game and player are imbricated in the cultural process of the production of meaning; in the process of reading the text or playing the game, an individual is positioned by its interpellative strategies - that is, the ways in which it 'hails' or addresses the player as a particular kind of subject — and that subject positioning can be explained in relation to the context in which the text or game was written or produced. Richard Alleva notes, for instance, that Monopoly, which was produced in 1934 and had its first massive success in 1935 , positioned its winner as a successful capitalist at precisely the moment in history when capitalism in the real world was entering a period of crisis in the Depression (Alleva 2003, p.22). Like Monopoly, The Sims positions the successful player as an efficient consumer in relation to a capitalist society.

Certainly, in spite of the reservations of some games theorists, productive work is currently applying theory developed in relation to the study of literary fiction to the gaming experience. For example, Henry Jenkins argues that there is significant continuity between the gendering of spaces in children's literature and in digital games (Jenkins 1998, p.277). His comparative analysis is effected by focusing on the cultural implications of spatial aspects of textuality. He suggests that: "The "adventure island" is the archetypal space of both boys' books and boys' games — an isolated world far removed from domestic space or adult supervision... a world that fully embodies the boy culture and its ethos' (p.279). Girls' books, on the other hand, 'describe naturalistic environments similar to the realm of the reader's daily experience' (p.281). Jenkins focuses on the spatiality of games as part of a historical and cultural continuity including literary texts, a comparison made possible by analysing the cultural implications of textual constructions of space for the production of gendered reading subjects.

Modally, The Sims as computer simulation is historically new, but generically, the space for play it offers, a constructed model of social experiences familiar to the player, is analogous to a genre with a long history in narrative fiction, that of the literary utopia. As Ben Hourigan has noted, videogames have 'potential for spatio-temporal utopianism....allowing players to simulate...environments they may personally view as utopian' (Hourigan 2003, p.55). While Hourigan's analysis focuses on role-playing games, key elements of simulation games such as The Sims, Sim City, and Sim Life are clearly structurally similar to the literary genre of utopia. Indeed, an interest in the history of the utopian city and utopian urban planning is often cited in profiles of Will Wright, the designer of these games. The construction of the alternative social space of The Sims has many elements in common with the founding 


\section{How easily and seductively it can align us with those values by making us want to succeed in the game.}

narrative of the genre, Thomas More's Utopia (1516), and with its intertexts. These fictions construct spatial and social arrangements alternative to those of their author's own cultural context, and utilise the projected narrative spaces to speculate about the effects of these 'more perfect' arrangements on human subjects (Suvin 1979, p.49). For example, in Utopia the institutions of the projected alternative society produce a capacity for compassion in its citizens exceeding that of More's contemporaries, in spite of the fact that the Utopians are pagans without the benefits of the tenets of Christianity. Similarly, a more contemporary utopian text - Ursula Le Guin's The Left Hand of Darkness (1969) — constructs an alternative society that functions 'more perfectly' in the absence of sexual binarism (Jameson 1975).

In The Sims, players can construct characters, build them mansions equipped with swimming pools and hot tubs, surround them with family and friends, and maintain them in highly successful careers such as 'superstar'(salary $\$ 1400$, bonus \$2800), acquiring and deploying commodities on their behalf, and managing their resources with a controlling power that develops with game skills. This is certainly a 'more perfect' world than that of most players. It could be argued, too, that like the reader of the utopian text, the player occupies an active position (Ruppert 1986, p.6), that reads the alternative space of the game in relation to the less perfect world of 'RL' (gamespeak for real life). This potential for an active shuttling back and forth between virtual and actual social experiences seems to suggest that The Sims, like the literary utopia, could engage the player in speculative thinking in relation to the social, encouraging 'what if?' questions about the implications of the alternative space, so that playing the game could potentially help players to develop an enhanced awareness of how their own cultural context positions them as subjects and mobilises their desires.

But The Sims does not position the player in the way that the literary utopia does its readers, and an exploration of the reasons for this reveals much about the ideological implications of the game-player relationship in this social simulation. While The Sims can be read as constructing alternative, 'more perfect', social spaces, it does not fulfil an essential criterion for the utopia in Darko Suvin's now canonical definition:

utopia is the verbal construction of a particular
quasi-human community where sociopolitical
institutions, norms and individuals relationships
areorganizedaccording to amoreperfectprinciple
than the author's community, this construction
being based on estrangement arising out of an
alternative historical hypothesis.
(Suvin 1979, p.49)

This concept of estrangement is central to the way in which the classical utopian texts position the reader. The term 'estrangement' means to represent familiar, naturalised, social phenomena in ways that relativise them, rendering them obviously cultural. For example, in Utopia More represents a society in which gold is so little valued that it is used to manufacture chamber pots. This representation has the effect of estranging — revealing as culturally constructed and contingent - the over-valuing of gold in early modern England. The reader is positioned to compare the two societies, the real and the projected, in an active reading. As Peter Ruppert has argued, it is this estrangement, or defamiliarisation for the reader, of the contemporary social context of the author, which produces the active reading position of the utopian text. The comparison with the projected alternative society produces in the mind of the reader a critical understanding of the inadequacies of the present society (Ruppert 1986). It is certainly the case that some aspects of The Sims seem intended to produce an estrangement effect. For instance, a key element of the game's material dimension — defined by Jesper Juul as the details of its settings and objects (Juul 2001, Section 6) - is that players need to 'buy' commodities by clicking on an icon. The descriptions of these objects, displayed on the screen so that the player can choose between them, are parodic of advertising prose. Next to the picture of a table the player can 'buy' to decorate a Sim house, for instance, the text reads: 'The Pinegulcher end table_\$40: Pinegulcher means value. Made of machine chipped and glue-hardened rubberwood, our accent tables are vacu-laminated to ensure minimal formaldehyde emissions. This contributes to the optimum strength and smooth finish on all surfaces' (The Sims). This satirical treatment of the representation of the commodities acquired in the game seems analogous to 


\section{How thoroughly imbued with the ideology of late capitalism the game is.}

the representation of gold in Utopia, so that the activity of playing The Sims might conceivably interpellate an active reading position interrogating consumerism.

It is certainly the case, too, that the constraints of consumer capitalism are built into the game's logic, so that in spite of the open-endedness of the game's ergodic structure, ultimately the goal-orientated nature of the game as a simulation of late capitalism could arguably produce an estrangement effect that might allow for the defamiliarisation of the socioeconomic conditions of the player's RL environment. A game logic according to which the acquisition of consumer goods improves mood; improved mood enhances work status; relationships are instruments for mood-enhancement, and therefore also improve work status; and improved work status enables further acquisition of consumer goods, seems designed as a critique of the dynamics of consumerism. If gameplay encouraged the capacity to see the structures and implications of the construction of the subject in relation to consumption in postmodernity, the game could indeed be defined as a utopian narrative.

In The Sims, however, the 'reader' of the game's alternative social spaces is also a player in the game, and the activity of reading/playing takes place in the tightly controlled 'feedback loop' between game rules and game play that constructs simulations. As Gonzalo Frasca notes:

\begin{abstract}
Simulation is the act of modelling a system A by a less complex system $B$, which retains some of $A$ 's original behaviours...For example Sim City 2000 (system B) simulates a city (system A). As a system, Sim City is less complex than an actual city. (i.e. there is no graffiti on the walls in Sim City, nor advertisements on the streets), but it retains some of its behaviours (i.e. buildings need electricity, and roads cost money to build).
\end{abstract}

(Frasca 2001, p.1)

Thus the simulation is always an extrapolated, rule-based model of the social, programmed to teach the player how the rules work. As Will Wright describes it, the process of gameplay is that of 'an adaptive system, which is the player, slowly approaching this model on the computer, getting closer and closer in their mind to understanding the way that model works' (Pearce 2002, p.5). Jorgen Kirksaether argues that:

Playing a game involves manipulating a graphic interface between the player and the game logic...The appeal of games isn't in mastering a complicated set of controls, but rather in submitting to a set of rules and trying to accomplish something under these rules' restrictions. When you play a game it may seem like you are 'playing the interface', but what's really happening is thatyou're trying to figure out the game's logic.

(Kirksaether 1998, pp.5-6)

Ultimately then, the modality of the computer game subordinates its material (descriptive elements of the game such as the 'ads' for commodities) to the game's encoded rules as the player strives to produce successful outcomes for the avatars. This limits the capacity of a simulation to offer the player an active reading position in relation to the actual social referent from which the game's rules are an extrapolation. As Sherry Turkle has argued in relation to an earlier Will Wright simulation game, Sim Life, the experience of simulation can work to reinscribe rather than contextualise and defamiliarise the RL social: 'Even though these rules are complex, they sustain the sense of a reassuring, rule-based world' (Turkle 1996, p.67). She adds: 'Games such as Sim Life teach players to think in an active way about complex phenomena as dynamic evolving systems. But they also encourage people to get used to manipulating a system whose core assumptions they do not see, and which may or may not be true' (p.70). Described in this way, The Sims is arguably what Louis Marin has defined as a degenerate utopia.

Like Suvin and Ruppert, Marin sees the production of an active, interrogative reading position as a hallmark of the classical utopian text, so that 'the utopic dialogue has a critical function. The representation of the ideal city, of its mores, institutions, and laws - precisely because it is picture and representation - conjures up, as a negative referent, real society; it thus encourages a critical consciousness of this society' (Marin 1990, p.79). Furthermore, unlike more straightforwardly satirical constructions of the social, utopian narratives function representationally by 'establishing transgression as a 
norm or law' (p.79). For example, in More's Utopia, 'the fundamental defining law is the transgression of private property' (p.79) because the text constructs an alternative society in which a shared life takes place in the absence of any exchange of money. This transgression is effected by a kind of excision, so that incipient capitalism, with its attendant wealth and greed, is not operative in Utopia, and its absence in the society has the effect of positioning the reader, through the estrangement process, to become actively aware of its omnipresence in the culture in which the text was produced. The utopian text thus positions its readers to interrogate the real world of which its alternative society is a projected other.

Marin suggests the term 'degenerate utopia' for texts which, while potentially utopian in their construction of an alternative socio-temporal space modelled in relation to the contemporary social world of their producer, function very differently from the classical utopias. Rather than excising key elements of the contemporary social structure so that the alternative society functions around a determinate absence registered by the reader, the degenerate utopia involves the reader in an experience of enacting key elements of the contemporary social, so that they are naturalised, and dominant understandings of the social are reinscribed and reinforced. Marin's instance of such a text, in the broad, semiotic sense of the word as a site of the production of meaning, is Disneyland. He suggests that Disneyland has key elements of utopian textuality: the space of the carpark through which the visitor enters Disneyland represents the 'break' that signifies the entry into the world of the classical utopian narrative - analogous to the shipwreck or the loss of consciousness that marks off the world left behind from the space of the alternative utopian society that is about to be encountered. The map of Disneyland sold to the visitor with the entry ticket has the function, as does the description of the new society in the classical utopia, of the 'represented picture of utopia', while each tourist's experience of a specific Disneyland tour (Fantasyland, Adventureland) has a function analogous to that of the utopian narrative in the classical utopian text. But for Marin, each tour, while potentially utopian, in that it offers the tourist a representation or staging of America's past and present social structures and institutions, is actually the result, not of a process of excision, but of a kind of intensification, in that it is the product of an already-coded myth of American culture, a rule-driven extrapolation from the real social referent. Central to the version of America staged in Disneyland is the triumph of commodification, so that visitors to Disneyland witness a version of 'American history predicated on consumption: the consumption of natural resources; the consumption of the frontier; and a future defined by consumption' (p.250). Marin argues that the centre of Disneyland, both literally and semiotically, is Main Street USA; it is the focus of all the radiating axes along which the tours take place, and the place to which the visitors return to acquire the objects that signify their acquisition of this symbolic history, as consumable image:

Main Street USA is the place where the visitor
can buy, in a nineteenth-century décor, actual
and real commodities, with his real, actual money.
Locus of exchange of meanings and symbolism in
the imaginary land of Disney, Main Street USA
is also the real place of exchange of money and
commodity.

(Marin 1990, p.247)

Rather than excising a key element of the contemporary social structure as texts in the Morean tradition do, so that the alternative place serves to return the reader to their contemporary society with a clearer sense of its structures and their historical implications for subjects, Disneyland, for Marin, is a degenerate utopia because its visitors are immersed in a distilled extrapolation from the social in which a key element - its structuration in relation to symbolic consumption - is naturalised, offered as a space for pleasurable engagement and immersion, and thus reinforced and internalised, rather than defamiliarised.

Just as the visitor to Disneyland has a sense of having an individualised experience, so too, the player of The Sims feels as if every instance of gameplay is a unique one, and has a sense of making new stories. Certainly the player seems to engage in open-ended narrative experiences: with each game different characters can be constructed, with different skin colours, genders, features, body language, clothing and names; new houses can be built and provided with different furnishings; different life trajectories can be plotted. But in The Sims, as at Disneyland, the utopian 


\section{It is precisely that sense of agency that is so worrying.}

narrative possibilities suggested by aspects of the game - the sense of having entered an alternative world analogous to the 'real' world, the feeling of being given a picture or representation that will provide a comparative reading of that 'real' world - are ultimately constrained by the game's underlying and generating code, which mobilises only a reduced model of the social, so that an experience that seems to involve an opportunity to read the social in play - similar to the sense of having the opportunity to learn about the realities of the social history of America from the tours of Disneyland - is actually only a performative internalisation of those rules in order to experience the pleasure of game success. What never changes is the coding of the simulation, and that encodes game goals which reinforce, rather than staging and defamilarising, the dominant.

According to the PC Power Play Game Guide: Your Essential Guide to The Sims (2004), 'The main aim of The Sim's 'success' is measured by how well-adjusted, happy, healthy and prominent your Sim is' (p.22). In order to achieve this game goal the player manages animated figures as they negotiate the simulated world of the game. Playing The Sims involves constructing characters from a menu of selections: male/female; white/black; adult/child. Configuring a Sim by gender, race and age allows the gamer to proceed to choose a hairstyle/face and outfit. Once the Sim has been physically modelled by choosing gender, race, hairstyle and clothing its personality must be configured. There are five 'Personality' traits ('Neat'; 'Outgoing'; 'Active'; 'Playful' and 'Nice'), and a box on the screen offers a 'points bin' with ' 25 points that can be assigned to whatever trait combination you choose to compose your Sim's character' (Sims Manual pp.17-18). Once the player has constructed one or more figures in this way they can be given both first and family names. The player is then offered the chance to type in a brief biography for each character before finalising the family. The next step in the game is to move the family of Sims into the Neighbourhood, choosing or building, furnishing and decorating a family home before securing employment for one or more family members, so that the Simoleons (Sims dollars) they earn can enable them to live successfully. The player then must manage the lives of the avatars in relation to a series of monitoring devices. Time is quantified in game minutes, marked as they pass on a digital clock, while wellbeing is quantified by bars that glow green or red according to whether the elements they measure are in credit or deficit. Each Sim is managed by attending to the eight Need Bars (Energy; Comfort; Hunger; Bladder; Hygiene; Fun; Social and Room), which must be must be kept green by constant activity. Combined, these ratings determine a Sim's 'Mood', which determines capacity to find employment and to succeed at it, as well as to sustain relationships. For example, to get a promotion at work a Sim must go to work in a good mood. This requires the player to make sure that its Hunger bar is full enough, and that its Bladder, Comfort, Hygiene, Social, Fun and Room indices are satisfactory. The player is counselled: '[O]ne of your chief concerns in Sim management is to make them happy through Mood management. Their happiness is the key to moving them forward in life, expanding their opportunities and chances for new experiences and relationships' (Sims Manual, p. 22).

Failure to manage a Sim's life effectively sees its mood deteriorate: the body language of the figure becomes agitated, and its 'voice' — they speak a gibberish-like 'Simlish' that conveys mood through pitch and tone, but only conveys ideation through simple pictographic symbols - becomes increasingly irritated. As its mood spirals downward it refuses to go to work, so that the supply of Simoleons rapidly dwindles. The player is ultimately confronted with a simulated world in which the failed Sim dies and is replaced by a tombstone. Successful gameplay in The Sims involves managing the social environment by mastering the encoded rules.

The simulation game seems analogous to the utopian narrative up to a point, because the modelling process in simulation does excise aspects of the real referent, stripping away some of the 'messy, uncontrollable and chaotic' aspects of that world (Hertz 1997, p.218). In The Sims, children never age and there are no taxes. But the less complex, relatively attenuated, social space produced by the game does not constitute a utopian narrative space, because while the game's code renders the pared-down world manageable, the player's experience is of the internalisation rather than the estrangement of the structural logic of the contemporary social. The simulation intensifies 
key social relations in a distilled form and then invites the player to enact them, become immersed in them and learn to manage them, and in the process become accustomed to 'manipulating a system whose core assumptions they do not see...' (Turkle 1996, p.70). The simulation in The Sims is an attenuated version of the social that can be successfully managed through consumption. It encodes human subjectivity as a system of five personality traits, and eight needs that can be quantified. Significantly, four of the five traits defining the subject have to do with the capacity to interact socially and to manage others through that interaction - the ideal characteristics of the subject of consumer capitalism. The relationship between traits and needs is manifested in mood, so that constant monitoring and adjustment of the needs indices is required to maintain mood.

Only through successful acquisition and deployment of commodities can Sims' needs be met and moods kept elevated, and the successful player is a discerning 'consumer' able to address multiple needs simultaneously. The game's website suggests that 'you'll have to experiment with all of the different objects to find out which ones are really the best' (The Sims website), and the manual advises that: 'Part of knowing your Sims well is in directing them toward obtaining and using... high quality objects. Your motivation for buying better things is strategic: you want your Sims to make more money so they can get more objects that more easily or efficiently fulfil their needs' (Sims Manual, p.24). The manual describes the trajectory of any given game in relation to the underlying game code: 'It's critical to bring in needed cash to a household's coffers with a good job. Your Sims need better household objects to move along more efficiently in the game. So, pay attention to the basics: Get your Sims to work on time, keep them practicing and studying in their chosen profession, work on making friends and they'll move up the ladder' (Sims Manual, p.15). Players are advised that 'The ratings are a good general guide...each item for sale has a number linked to the needs bars - a more expensive bathtub will bring both hygiene and comfort points...a Sim's hunger needs are better met with an expensive stove' (Sims Manual, p.24).
Central to game success is an instrumentalist orientation toward other occupants of the Neighbourhood; they are seen as objects for deployment in the goal of advancing the family being played at the time. The website advises that:

\section{It can be difficult to make friends when first starting out because there are not very many Sims in the Neighbourhood. When first starting, it's generally a goodidea to move in eight Sims with high Outgoing and Nice points into every lot. You can evict them later when you want to move another family in. (The Sims website).}

The website further suggests that: 'Atwo-member family is the best size to keep your Sims' Social up. A third member of the family might be good to manage household chores and procure friends so the other Sims can focus on skill building and maintaining a positive mood' (The Sims website). The acquisition of commodities is linked to this project of harnessing others to the goal of Sim success. 'The hot tub is by far the best value in the game because it contributes to three motives (four, if there are other Sims in the tub). It can be used to replace any fun/bath objects and it's also a great way to put visiting Sims in a good mood to increase the likelihood of a positive result from an interaction' (The Sims website).

Time, too, is commodified in The Sims, as its 'spending' must be consistently monitored, so that it becomes a kind of currency. Rather than controlling time in the game, the player is controlled by it, and that rule of the social is naturalised by the game code. Within the action of the game, time is made manageable by efficient commodity acquisition: 'A small TV is less efficient at entertaining than a large TV. To put it in more analytical terms, in order to maximise the efficiency of each Sim, it's necessary to find out how to make them happiest in the least amount of time' (Sims Manual, p.24). Time speeds up when the Sim gets into the car to go to work; the hours of labour race past, and then time slows down when the Sim returns home having earned enough Simoleons to begin the round of consumption over again. One way to pause the relentless clock, that ticks away the hours devoted to keeping the Need bars full and the Sim's mood elevated so that they can go to work again the next day, is to enter 'Buy' mode. 


\section{We are moving on here to the question of subjectivity, the kind of person being created through interactions with material on a topic in a range of media and with multimodal texts.}

This has the effect of pausing the game while the judicious purchase is made, so that the act of 'shopping' has the effect of stopping the 'spending' of time. As well, the strategic acquisition of labour — a maid or a gardener - buys time for the acquisition of skills that can enhance career prospects. Thus, the game immerses the player in the project of managing time through the acquisition of commodities, naturalising through pleasurable engagement with the game's logic, the key aspect of consumption capitalism - 'time is money'. In The Sims, time is the most precious commodity of all, and can be controlled by efficient lifestyle management through the manipulation of resources and commodities. The game also links temporality to consumption in a broader sense, as it naturalises and teaches the player to manage, rather than to interrogate, the temporal logic of late capitalism. The life trajectories enacted by the Sims can be cancelled and the game of life restarted over and over again, as the player comes closer and closer to internalising the rules, so that the game of life can be practised and perfected, a fantasy manifest in a number of contemporary film texts, such as Groundhog Day and Eternal Sunshine of the Spotless Mind.

It is clear from this description of the rules for game success that The Sims distils and intensifies, through its underlying code, key ideological aspects of late capitalism: self, other, and time are all quantified and commodified. What the player is doing is shopping effectively in order to manage a life in the world. The Sims does not use the extrapolative process of modelling the simulation to distance the player from the projected world, as speculative utopian fiction would, but instead naturalises it by immersing the player in an interactive environment that offers an opportunity to oversee lives made controllable through commodification. The Sims offers the pleasure of playing in an extrapolated and pared down social context in which 'making it' can be effected by learning the rules and bringing a developing understanding of the game's underlying logic to bear on the avatars. The achievement of gameplay mastery is a tightly limited loop: rewards come from acquiring commodities and transforming them into a further capacity to manage resources. Arguably gameplay constitutes, in a fantasy displacement, imagined mastery of the real social of which the game offers itself as a model. The player is efficient consumer and lifestyle manager, and while the commodities being acquired are not real, but only images that contribute to the construction of a imagined lifestyle, the same, as Guy Debord has argued, can also be said of the process of commodity acquisition in the real social of late capitalism (Debord 1977). The rules of the game can thus be seen as an intensification of postmodern commodity culture rather than as a utopian projection based on transgression. Thomas Bean and Karen Moni have argued that:

Identity in a mall culture is constructed through
consumption of goods, with selfhood vested in
things. Because this is ephemeral, feelings of
panic and anxiety flow into teens lives. In this
context, identity is not an essence but a problem
to be undertaken by the actor. Postmodern forms
of urban teen identity include cults of performance
manifested in consumption of goods that form or
alter identity...
(Bean and Moni 2003, p.641)

While real material consumption on the scale required for mastery as defined by commodity culture - that is, an affluent lifestyle - is beyond the economic means of most players, the pleasure of commodity consumption at the level of the sign is afforded by the game. A player enacting the multiple narrative trajectories in the ergodic mode of this simulation is uttering the story of the complex imbrication of subject, time and commodity in consumer culture. If, as Sherry Turkle has argued, young people in postmodernity 'need to compensate for a vulnerable identity by establishing a sense of control' so that worlds of simulation make them feel like 'masters of the universe' (Turkle 1996, p.30), in The Sims, that control, achieved by successful internalisation of the game rules, makes possible the pleasurable performance of 'the consumption of consumption' (Jameson 1991, p. 276).

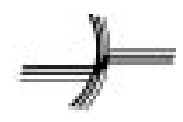




\section{ACKNOWLEDGEMENTS}

I would like to acknowledge productive discussions about The Sims with Jennifer McGuire, Sean McGuire, Laura Money and Suzanne Yates.

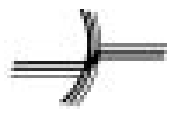

\section{REFERENCES}

Aarseth, E. (1997) Cybertext: Perspectives on Ergodic Literature. Baltimore and London, Johns Hopkins University Press.

Aarseth, E. (1999) 'Aporia and epiphany in Doom and The Speaking Clock: The temporality of ergodic art', in Marie-Laure Ryan (ed) Cyberspace Textuality: Computer Technology and Literary Theory. Bloomington and Indianapolis, Indiana University Press, pp. 31-41.

Alleva, Richard (2003) 'Keeping up with the Simses', Commonweal 130, 4: 22-24.

Bean, Thomas W. and Moni, Karen (2003) 'Developing students' critical literacy: Exploring identity construction in young adult fiction', Journal of Adolescent and Adult Literacy 46, 8: 638-649.

Debord, Guy (1977) The Society of the Spectacle. Detroit, Black and Red Press.

Douglas, Christopher (2002) 'You have unleashed a horde of barbarians: Fighting Indians, playing games, forming disciplines', Postmodern Culture: An Electronic Journal of Interdisciplinary Criticism 13, 1: 1-20. Retrieved June 28, 2004, from http://www.iath.virginia.edu/pmc/text-only/ issue.902/13./contents.html

Frasca, Gonzalo (2001) 'Simulation versus representation', Ludology http://www.ludology.org/articles/sim1/ simulation $101 \mathrm{c} . \mathrm{html}$

Green, B. and Bigum, C. (1993) 'Aliens in the classroom', Australian Journal of Education 37, 2: 19-41.

Hertz, J.C. (1997) Joystick Nation. Boston, New York, Toronto and London, Little, Brown and Co.

Hourigan, Ben (2003) 'The utopia of open space in role-playing videogames', Ezine: Special Issue DAC 2003 Conference Papers. Melbourne DAC, 17.8. Retrieved June 15, 2004, from http:/www.fineartforum.org/ Backissues/Vol_17/faf_no8/reviews/hourigan. html

Jameson, Fredric (1975) 'World-reduction in LeGuin: The emergence of utopian narrative', Science Fiction Studies 7: online. Retrieved June 7, 2004 from http://www.depauw.edu/ sfs/backissues/7/jameson7art.html

Jameson, Fredric (1991) Postmodernism, or The Cultural Logic of Late Capitalism. London and New York, Verso.

Jenkins, Henry (1998) "Complete freedom of movement": video games as gendered play spaces', in J. Cassell and H. Jenkins (eds) From Barbie to Mortal Kombat. Boston, MIT Press, pp. 262-298.

Juul, Jesper (2001) A Clash Between Game and Narrative: A Thesis on Computer Games and Interactive Fiction. English translation of a Masters thesis [electronic version]. Retrieved June 12, 2004,from http://www.jesperjuul. $\mathrm{dk} /$ thesis/6_readings.html

Kirksaether, J. (1998) 'The structure of video game narration', Digital Arts and Culture. Retrieved June 29, 2004 from http://cmc.uib.no/dac98/ papers/kirksaether.html

Le Guin, Ursula (1969) The Left Hand of Darkness. New York, Harper \& Row. 
Manovich, Lev (2001) The Language of New Media. Boston, MIT Press.

Marin, Louis (1990) Utopics: The Semiological Play of Textual Spaces (translated by Robert A. Vollrath). Atlantic Highlands NJ, Humanities Press International, Inc.

Pearce, Celia (2002) 'Sims, battle bots, cellular automata, God and Go: a conversation with Will Wright', Game Studies: The International Journal of Computer Game Research 1, 2: 1012, http://www.gamestudies. org/0102/pearce

Ruppert, Peter (1986) Reader in a Strange Land: The Activity of Reading Literary Utopias. Athens, Georgia, University of Georgia Press.

Suvin, Darko (1979) Metamorphoses of Science Fiction. New Haven and London, Yale University Press.

Suvin, Darko (1998) 'Utopianism from orientation to agency', Utopian Studies Spring 1998 [electronic version] Retrieved June 17, 2004 from http://web5.infotrac. galegroup.com.dbgw.lis.curtin.edu.au/itw/ infomark/685/572/5106
The Sims (2000) Macintosh PC Game. Designer: Will Wright. Developer/Publisher: Maxis/ Electronic Arts.

The Sims Deluxe Edition Manual (2003) Singapore, Electronic Arts.

The Sims website: http://thesims.ea.com/us/about/ tips

Turkle, Sherry (1996) Life on the Screen: Identity in the Age of the Internet. London, Weidenfeld and Nicolson.

Zancanella, Don et al. (2000) 'Computer games as literature', in Andrew Goodwyn (ed.) English in the Digital Age. London and New York, Cassell, pp.87-103.

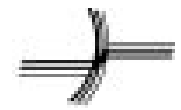

\section{BIOGRAPHICAL NOTE}

Ann McGuire is a Senior Lecturer and Director of Undergraduate Programs, Department of Communication and Cultural Studies, Faculty of Media Society and Culture, Curtin University. 